\title{
EDITORIAL
}

\section{String Music: Creating Coronary Artery and other Vascular Anastomoses}

\author{
Curt Tribble, $\mathbf{M D}^{1}$, Stephen Derryberry, $\mathrm{MD}^{2}$
}

\author{
${ }^{1}$ Division of Cardiac Surgery, University of Virginia Health System, Charlottesville, Virginia, USA; , ${ }^{2}$ Department of Surgical
} Sciences, Vanderbilt University, Nashville, TN, USA

\section{INTRODUCTION}

The initial version of this treatise was written as I (Curt Tribble) was learning to do coronary anastomoses over 30 years ago, and I worried that I was not being taught very well how to go about doing them. It seemed to me that my teachers were channeling Dr. Alain Carpentier, who often answered questions about his mitral valve repair techniques by saying, "Oh, you just know." These frustrations were compounded by the fact that the best cardiovascular techniques books, including even those texts dedicated to coronary artery bypass techniques, did not describe these anastomotic techniques in detail, which remains the case to the present day [Kaiser 2007; Copeland 1986].

Of course, no one is born knowing how to repair mitral valves or how to create small vessel anastomoses, such as those to coronary arteries. The technique to be described can be used for all end-to-side anastomoses being made to smaller vessels, such as tibial arteries and coronary arteries. Though it is true that not all cardiovascular surgeons do their anastomoses in this way, this technique is a reliable and versatile way to do them. Furthermore, very importantly, this technique can be taught to cardiac surgical trainees, even to those who are beginners. In fact, I must admit that a great deal of my own evolution as a teacher of cardiovascular surgery required me to be able to describe precisely what I wanted my trainees to do, both accurately and in detail. Eventually, I found myself slowly but surely getting better at describing these techniques to my trainees. I also realized that if I could write out precisely what I wanted my residents to do, and have them read through such a treatise, I could be much more efficient in the operating room, both in getting cases done expeditiously and in helping my residents become capable cardiovascular surgeons, and eventually teachers themselves [Tribble, 2017].

Obviously, a lot of preoperative planning is required to sort out which vessel or vessels should be grafted, and where those vessels should be opened for the anastomoses. We will cover those aspects of vascular anastomoses in a separate treatise. Positioning the heart to optimally

Correspondence: Curt Tribble, MD, Professor of Cardiothoracic Surgery, University of Virginia Health System, Division of Cardiac Surgery, Box 800679, Charlottesville, VA 22908; 434-243-9250 (e-mail: ctribble@virginia.edu). expose and work with the target vessels when doing coronary artery bypass surgery will also be described separately.

\section{FIRST THINGS FIRST: A FEW SPECIFIC NOTES ABOUT NEEDLE DRIVERS}

The most common needle driver used for coronary anastomoses is the Castroviejo needle holder, but some surgeons use the Ryder needle driver (Figure 1).

The Castroviejo needle holder should be operated as you might handle chop sticks or a pencil that can be rolled in your fingers. This type of needle holder should not be driven primarily by wrist action. To be clear, you should sew larger vessels, like the aorta, with your wrist, using standard needle drivers. The round Castroviejo needle holder promotes this "finger roll" movement. However, it is also possible to roll the flat Castroviejo needle holder fairly easily on your fingertips, so you will need to get used to this movement if your program uses the flat Castroviejo drivers.

You should avoid continually realigning your needle in the driver. Most of the time when someone is doing this, they are just fidgeting and wasting time, which is sometimes described pejoratively as "stuttering." The needle should usually be loaded perpendicular to the needle holder, though the needle should be angled out at times. When sewing delicate tissue, position the needle near the tip of the needle driver (though, to be clear, the needle itself should not be grasped near its tip).
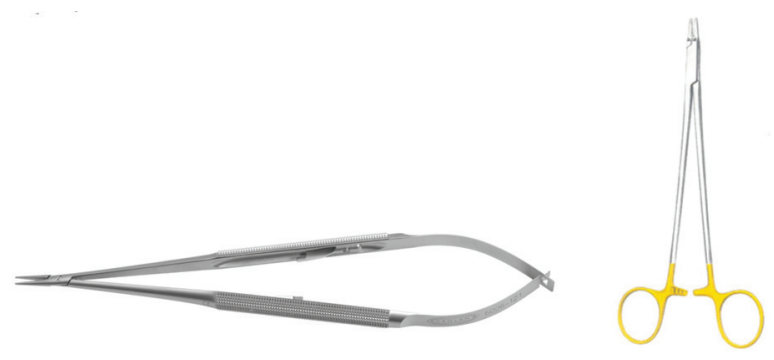

Figure 1. Two common needle holders used for vascular anastomoses: the Castroviejo Needle Holder (left) and the Ryder Needle Holder (right). 
For bites in tougher tissue, put the needle further back in the jaws of the needle driver where it will be held more securely. Be aware that the tip of a fine needle holder can cause injury to the vessel being grafted. Determine ahead of time how you want the curved cardiovascular needle to pass through the tissue, and then load it into your needle holder in the appropriate orientation to accomplish that goal. Be conscious of the fact that you don't want to do this in the opposite order. That is, think first about how you want the needle to pass through the intended target and then load the needle with the optimal angle, rather than loading the needle and then trying to make a suboptimal needle angle work.

Finally, remember that the ratchet, or "latch," of the needle driver is used primarily to allow the scrub nurse to pass the loaded needle driver to you. Therefore, you can, and many do, release the latch prior to passing the needle through the tissue, which not only avoids the occasional difficulty in releasing the needle but also holds the needle more securely than the latch alone will hold it.

\section{A SENSE OF WHERE YOU ARE}

Given that many small vessel anastomoses will be created "down in a hole," it is worth noting that it is important to not only visualize clearly what you are doing but to also maintain a feel for where you are in this three dimensional space. You can often brace your hand on the chest wall or the sternal retractor when sewing. However, bracing in this way is sometimes impractical. You can add to your sense of where you are by extending the fifth finger on your sewing hand so that it touches something stable in a deep hole. This will increase your proprioceptive awareness, which can supplement your visual awareness.

\section{DISARMING YOUR WEAPONS}

Finally, as often as is practical, disarm the needle in the needle driver when you are not sewing with it to reduce the chance of needle sticks to all on the team. You can turn the needle in the driver so that the point faces the driver, making it less likely to injure someone. You should also place the shod clamp to secure the non-working end of the suture below the needle, rather than on the needle itself. This makes the needle less dangerous as well, since a "floppy" needle is considerably less likely to be capable of sticking someone.

\section{CREATING A WORK SPACE: LIVING IN A COFFEE CAN}

Creating a work space in which to sew coronary anastomoses was colorfully described by one of my favorite colleagues, Dr. Bob Hannan, as, "living in a coffee can." This meant that one has to create a small space, free of clutter and distraction. This allows one to focus precisely on the challenging task of creating anastomoses in coronary arteries, which are often two millimeters or less in diameter (Figure 2).
When you are ready to graft a particular vessel, you should use towels to help create a proper work space. You need to cover all the things in the field that may catch the sutures. Use white towels when sewing with blue suture, and perhaps blue towels when sewing with white suture, like Gortex. You need to be able to see the sutures you're sewing with, not have them made less visible by the towels. Do not place these towels until you are ready to sew. This is especially true if you have been debriding something, like a calcified valve annulus, intraluminal clot, or an infected valve, as you want to keep your work space clean. The edges of the towels should be folded under, since they will lie flatter that way. And, you will want to orient the towels so that the suture is less likely to catch on a corner of a towel.

As an aside, when you are done with each anastomosis, you should give the towels back to the scrub nurse so that:

- You can keep them clean and ready for subsequent use.

- They won't fall off the table.

- You can see all the lines and clamps in the field clearly when you are not sewing.

\section{CREATING THE OPTIMAL OPENING IN THE TARGET VESSEL}

Once the vessel to be grafted is identified, palpated, and determined to be of adequate condition and size, it must be opened. Many surgeons open the vessel with a $15 \mathrm{C}$ scalpel blade, though others prefer various other scalpel blades, particularly those used in ophthalmic surgery. The key to this step is applying appropriate tension on all sides of the vessel to keep it stretched out, while remembering that exposure and retraction are the "king and queen" of surgical technique. You should start by holding the epicardium, or other surrounding tissue, with fine forceps to the side of the midpoint of the spot you think you want to open. Instruct your assistant to hold the epicardium with two fine pickups opposite you, with each placed beyond the extent of the planned incision in the vessel, while you hold the tissue on your side with your pickups. This allows

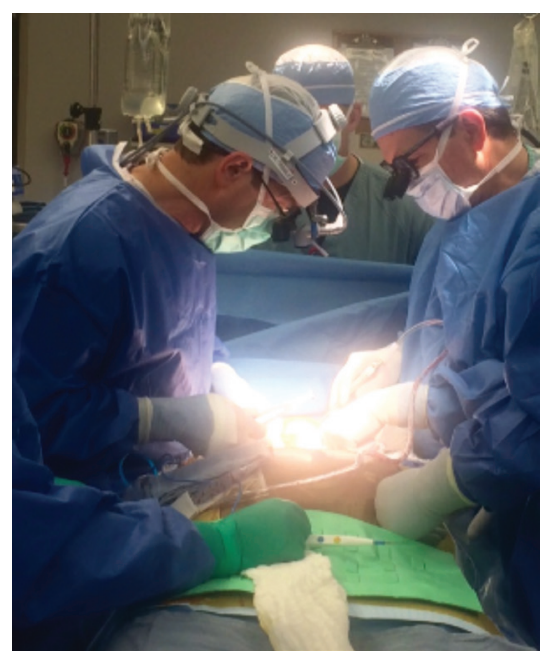

Figure 2. Creating a work space.. 

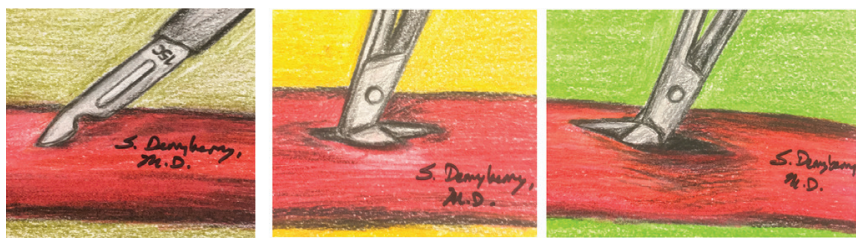

Figure 3. Opening the target vessel, cutting proximally first.

for "triangulation" that will optimize the tension on this tissue. If the epicardium is difficult to grasp, cutting a small slit in the epicardium off to the side will facilitate holding it securely. The belly of the scalpel blade is used to begin the cut: first in the epicardium, and then in the adventitia of the vessel. The epicardium should be opened a bit more than the envisioned arteriotomy, especially on the distal end, so that the target vessel can be visualized and palpated to ensure that there is no hard plaque or branch just beyond where you intend to work.

When preparing to open the vessel itself, remember that the knife should be used only to create a small opening in the target vessel, and that the arteriotomy will be subsequently fashioned more precisely with sharp Potts vascular scissors. The tip of the $15 \mathrm{C}$ scalpel blade is used to open the artery, rather than the belly of the blade. If the vessel has some disease in it, you should aim for the blue streak that will often be on the top of the vessel. Once the target artery has been opened with the knife, Potts scissors are inserted to open the vessel a bit more. One should usually cut proximally first, since that end of the arteriotomy is the less important of its two ends. Opening the vessel in the proximal direction first will provide better visualization for creating the optimal opening on the distal end of the arteriotomy.

Probes can be used to assure that you are below the obstructions you hope to bypass. Not everyone probes every vessel, though many surgeons do. If a probe is used, it must be inserted with great care. The proximal and distal ends of the arteriotomy must end up in the middle of the top of the vessel, even if the initial arteriotomy turns out to have been off to one side. It is more difficult to sew an anastomosis properly if the heel and toe are not on the top and in the middle of the vessel to be grafted. Proper opening of the vessel is, therefore, vital to constructing a well done anastomosis. Actually, it may well be the most important aspect of obtaining a satisfactory result (Figure 3).

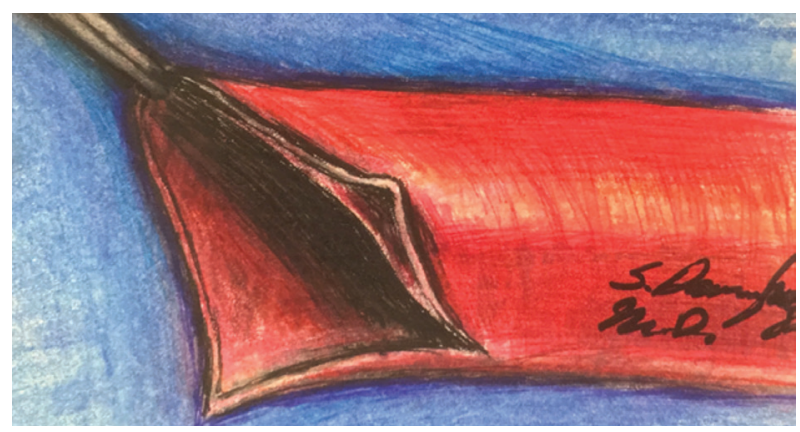

Figure 4. The "back cut" on the graft..

\section{TAILORING THE GRAFT}

The graft should usually be cut relatively straight across the end to be used if the graft is a vein or an artery, such as the internal mammary artery. However, if the graft is a prosthetic material, such as Gortex or Dacron, it should be beveled a bit. The graft is then "back cut" a bit in the axis of the graft on the side facing the planned anastomosis, so that the opening is, overall, at least slightly longer than the arteriotomy (Figure 4).

In fact, the goal should be to have the anastomosis end up being at least twice as long as the diameter of the graft. The back cut will also facilitate creating the optimal "angle of approach" of the graft to the target vessel, which should be about 30 degrees (Figure 5).

\section{DON'T BE TANGLED UP IN BLUE}

A rubber-shod clamp holding the end of the suture that you will not be sewing with should be placed on your side of the field and as near the arteriotomy as is feasible without being in the way. Positioning this non-working end of the suture is the first step of any continuous vascular anastomosis. Having the non-working end of the suture relatively near the anastomosis will make the most suture available for the anastomosis. Doing so will also make it less likely for that end of the suture to get caught on something, less likely to fall off the field, and less likely to get tangled up in people's hands or instruments. It will also allow enough suture for the optimal "following" of the suture by your assistant as the anastomosis progresses.

\section{START WHERE YOU WANT TO FINISH}

Decide where to start the anastomosis by deciding where you want to finish up. Usually you will want to sew continuously with the original needle all the way around the anastomosis. Therefore, you will want to start on your side of the heel of the anastomosis, which will allow the final stitches to be placed forehand (towards yourself) near the starting point on the heel. The person holding the vein should have two pairs of pickups to open the graft up for easy visibility of its lumen. The first stitch is taken in the graft about $2 \mathrm{~mm}$ away from the "crotch." This stitch is called the "shoulder" stitch. It is usually

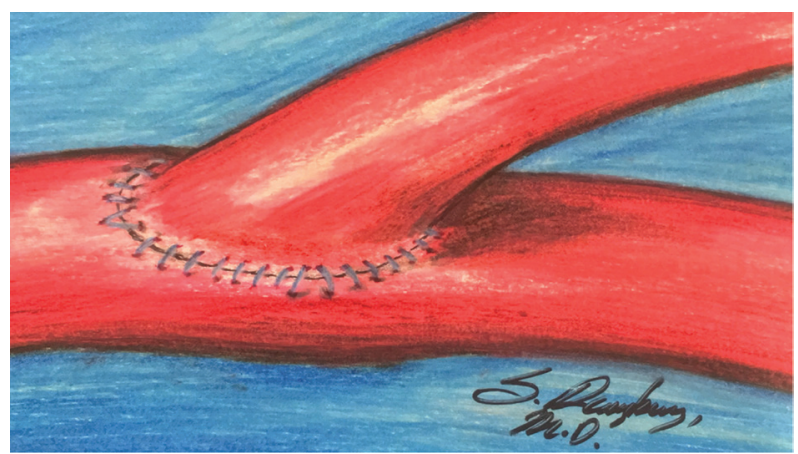

Figure 5. The proper "angle of approach" of the graft to the target vessel. 


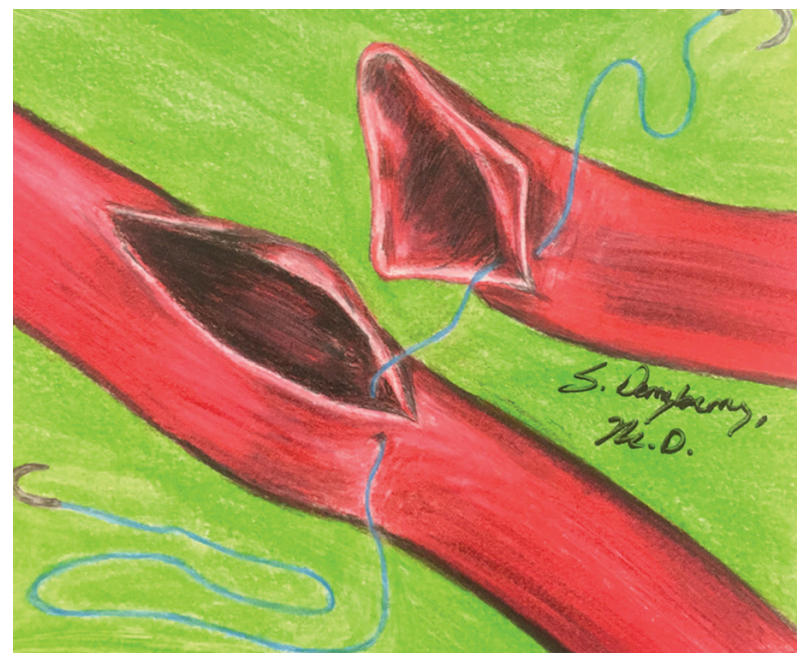

Figure 6. The shoulder stitch in the target vessel, placed inside out.

put through the vein or graft backhand and it is placed "outside in" on the graft. The next stitch will be placed "inside out" in the analogous spot on the artery being grafted (Figure 6).

Needles should be handled as much as possible with the forceps. Try to avoid picking the needle up with your hands, which is inefficient, hard to do, and somewhat dangerous. The needle should be reloaded in the depths of the wound if possible, but if this maneuver is awkward, the needle can be pulled up to the body wall on top of the towels, stabilized, and loaded again with your needle holder. The very tip of the needle should never be grasped with the forceps, as it is much too sensitive, meaning that it does not take much force or torque to injure the tip of a small vascular needle.

The needle is then passed through an appropriate corresponding point on the artery being grafted. Once again, the needle is pulled through the vessel with the pickups and

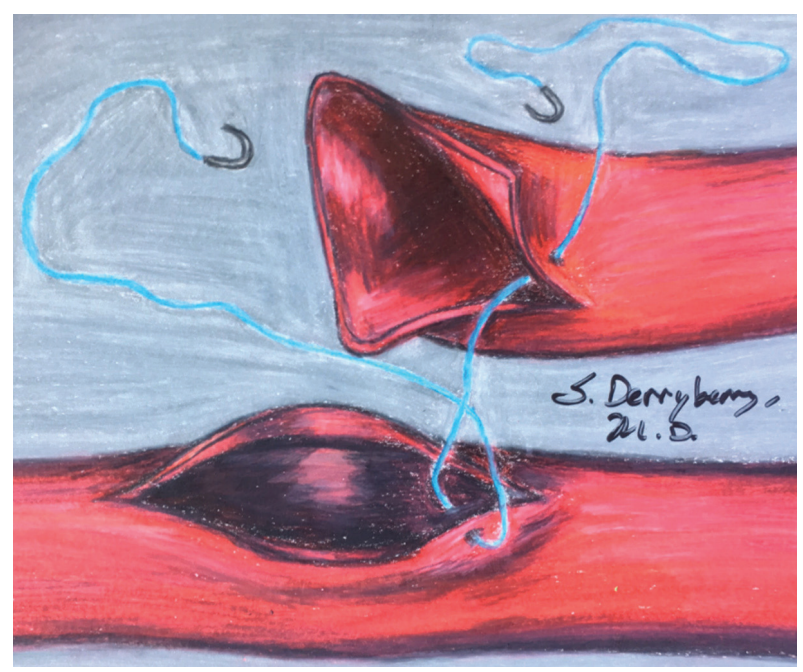

Figure 7. The shoulder stitch, pulled out and away from the surgeon. reloaded, while always reaching over all the strings of the open (or "parachute") anastomosis to pick up and reload your needle. From this point on, you will work away from yourself towards the other side of the arteriotomy with all loops of suture being pushed back toward you (Figure 7). The next stitch should be placed halfway between the first stitch and the apex. This stitch is called the "hip stitch" (Figure 8).

Remember that as one goes around the two ends of the anastomoses, very small bites should be taken both on the coronary and on the graft, avoiding both deep bites on the vessels and wide travel between the stitches. Otherwise, purse-stringing may occur and narrow the inflow of the graft to the coronary, particularly a small graft like an internal mammary artery. The stitches on either side of the midline should be particularly small, as deep bites at these points can narrow the vessel. This principle is more important in the toe (distal end) than in the heel (proximal end) of the anastomosis, but you often want blood to go in both directions, so both ends are important.

These stitches at the heel and the toe do not need to have as much strength as those on the sides, because the primary goal in the placement of these stitches is to achieve hemostasis. The strength of the anastomosis will be obtained with the deeper bites on the sides of the vessels. Some strength, and perhaps some hemostatic effect, can be added by picking up a bit of epicardium outside the coronary, particularly on the sides of the anastomosis. However, one must be very sure to neither drag epicardium into the lumen of the vessel nor into your line of sight, both of which can compromise the quality of the anastomosis. The way to snag a bit of epicardium is to pass the needle just through the cut edge of the epicardium. Again, the remaining stitches of the initial five that are placed in the apex will be the "hip" stitch on either side of the heel, and the "shoulder" stitch on the side away from you.

As these initial four or five stitches are being placed, the slack is pulled out of the loops of suture. This approach keeps some gentle tension on the suture at all times. It is essential to remember to reach over ALL loops of the suture as one prepares to take each bite. Whereas it is important to keep the

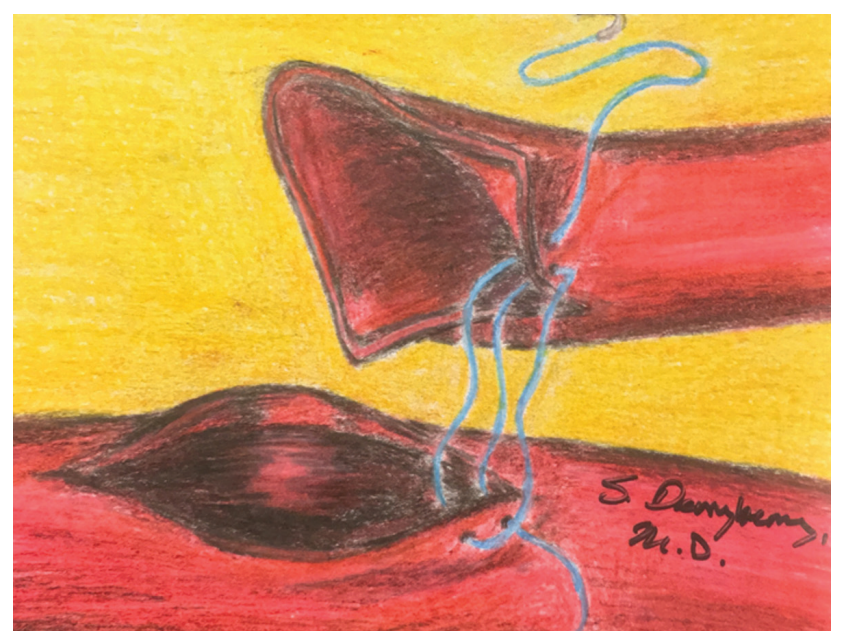

Figure 8. The completed hip stitch. 


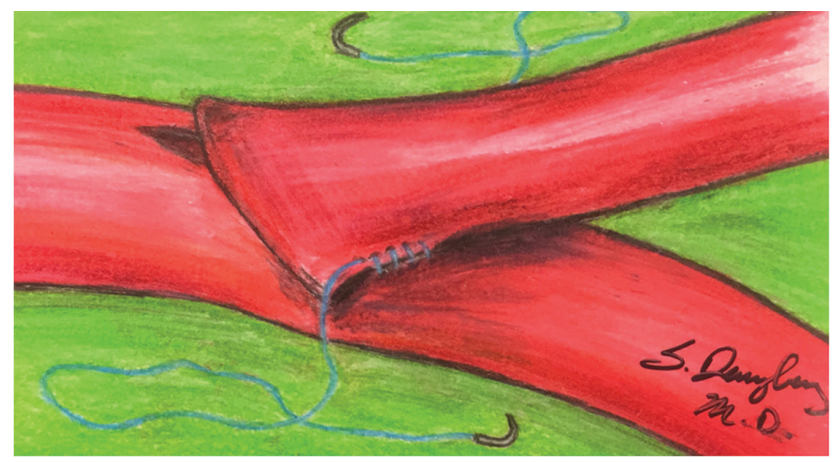

Figure 9. The graft pulled down onto the vessel being grafted.

slack out of the strings, you should not pull up so hard that the graft is inadvertently pulled down towards the vessel being grafted. An exception to this advice may occur when you actually do want to pull the graft down a bit, such as when the suture is short or when the vessel is deeper in the chest than usual, which functionally makes the suture shorter. There are two reasons to keep the loops of suture of uniform length and under some tension:

- You are less likely to get things tangled up in them.

- When you are ready to pull the graft down, the sutures will come down (tighten up) uniformly.

Five stitches can usually be used with vein grafts and when the wall of the coronary is tough. Four sutures should usually be placed for internal mammary artery grafts or if the coronary wall is thin. Otherwise, these initial sutures may pull through the graft or the vessel wall while parachuting the graft down, a process affectionately known as "the pull-down."

\section{THE PULL-DOWN}

The pull-down of these first four or five sutures is a dance. The goal is to pull the slack out of the loops of the suture by applying tension on both ends, while avoiding letting any of the loops get trapped by one of the others. You will want to try to pull a bit more towards the side you're going to continue sewing with, as any suture left behind will no longer be of use to you for the rest of the anastomosis. This dance involves having the person pulling the suture (the primary surgeon) do this intermittently, while the person holding the graft (the first assistant) allows the graft to come down with just enough tension to allow the loops to be pulled through evenly.

If the loops don't come down uniformly, the person pulling the suture needs to let up on the suture ends, and the person holding the graft needs to pull up on the graft to re-tension the loops (thus, pulling out the slack). If the loops aren't cooperating, the assistant can stick a pair of forceps into the circle of the loops of suture and allow the forceps to open gently to spread them back out, which will usually make the loops uniform again. If neither of these moves works to restore the uniformity of the loops, sort out the loops in some other manner, prior to pulling the graft all the way down, as once a loop is trapped, it can be difficult to pull it through. If all else fails, a nerve hook may be required to restore order to the loops (Figure 9).

Once the pull-down is complete, the shod clamp on the non-working end of the suture is repositioned. It should be repositioned so that:

- There is some tension on this end of the suture, both to keep it from getting snagged on things and to hold the vessel being grafted open a bit. The optimal position of the shod clamp on the field will usually be different from the original position of that clamp.

- The shod won't fall off the table.

- It will be out of the way while the rest of the anastomosis is constructed.

The assistant, if capable, should be in charge of this repositioning of the shod. However, you should not allow an inexperienced first assistant to be in charge of this move. It's too important to be delegated to someone unfamiliar with this process.

\section{STRING MANAGEMENT: FOLLOWING THE SUTURE}

Now you are ready to get on with the anastomosis, remembering that the heart is ischemic, so you will need to progress expeditiously. After reloading the needle after each bite, always hold the suture up so that your assistant can gain control of it and can follow the suture correctly and efficiently. If the assistant is skilled, he or she can help set the tension on the suture and on the graft after each bite in the vessel being grafted has been placed. If your assistant is not skilled (or not paying attention), then it will be your job to:

- Pull up on the string after each reload of the suture needle.

- Position the graft so that the proper amount of the graft is "set" to assure that there is no pleat, as a pleat left behind will almost always leak.

- $\quad$ Be sure that, if the graft is pulled down and there is a pleat, you backtrack right then and fix it. You can make this move with minimal time lost at this point, but it will take considerably longer to put in a separate repair stitch after the anastomosis is complete.

If the suture is too short (such as a 30 inch polypropylene suture, instead of 36 inch suture) or if you're working in a deep hole, it may be hard for your assistant to follow the suture efficiently. In such cases, consider putting rubber shod protector tips on a pair of DeBakey forceps to hold the suture. Doing this will allow not only proper tension on the suture (without risking hurting the monofilament suture), but will also allow the suture to be pulled out instead of up from the anastomosis, which will lessen the chance of "slotting" the vessel being grafted (Figure 10). 

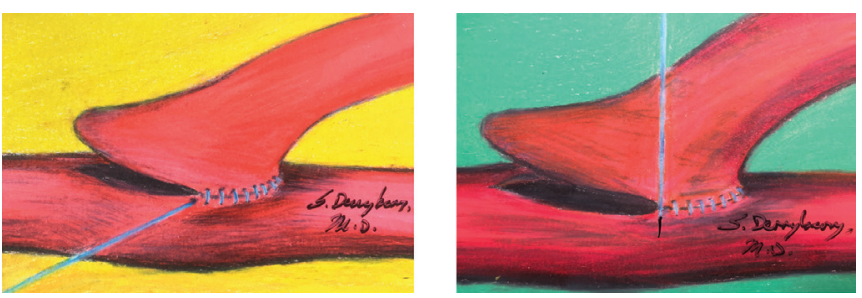

Figure 10. Pull out and not up to avoid slotting when following the suture.

As the anastomosis progresses, you will notice that sometimes the suture will become twisted. If this happens, the twists usually make it harder and harder to pull the suture smoothly through the tissues. If these twists do begin to make it harder to pull the suture through, stop and disengage the needle from the driver to untwist the suture. When pulling the suture up to reload your needle, remember that you do not need to touch the needle with your fingers. Slide your fingers up the suture, allowing it to untwist, and stop right below the needle. Not only is it easier to reload the needle this way, but also this technique will lessen the chance that you will get stuck by your needle.

As the creation of the anastomosis continues, your assistant should provide some counter traction on the graft, taking care not to injure it with the forceps, and at the same time continuing to follow the suture. The surgeon sews the first side of the anastomosis backhand. Sewing in this direction allows you to finish up sewing towards yourself at the point when it is harder to see the inside of the target vessel as the anastomosis is nearing completion.

\section{SEWING IN A CIRCLE: EVERY STITCH HAS A} STORY

As one moves down around the toe of the anastomosis, smaller and smaller bites should be taken, as they were in the heel. The stitches should be just a few cell layers into the coronary and a similar distance in travel, though the apical stitch in the distal end of the anastomosis can be a bit deeper than the two on either side of the apex, since the apical stitch won't narrow the lumen. You should take at least five stitches to make your way around the toe. These stitches should often be "two bite" stitches to get exactly the right bite in both the graft and especially in the vessel being grafted (Figure 11).

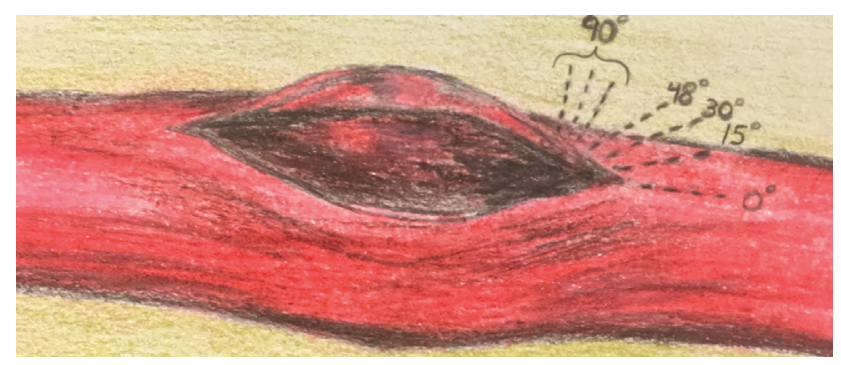

Figure 11. The optimal direction of needle placement around the apices of the anastomosis.

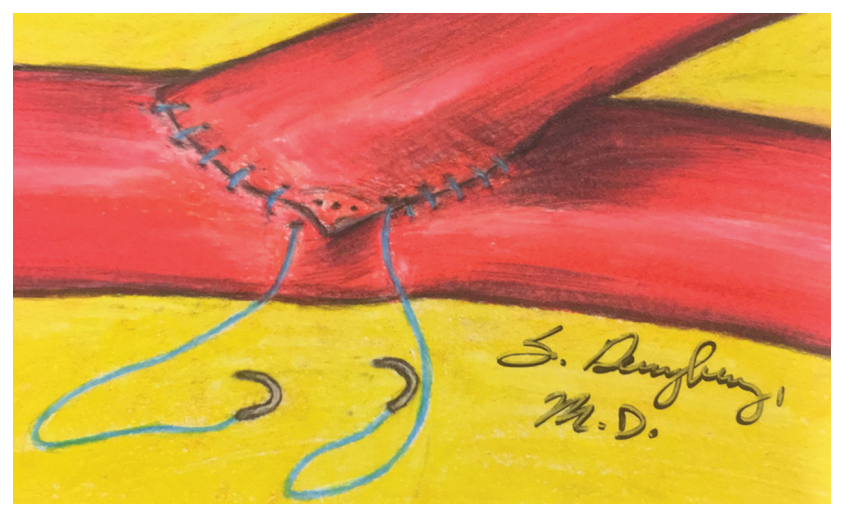

Figure 12. The dots on the graft demonstrate where the final sutures will be placed.

Extreme care must be taken not to catch the back wall of the vessel being grafted. One way to do avoid catching the back wall is to keep the needle cocked up anteriorly and to use the back of the needle to push the back wall of the coronary away. Using the needle in this way (to push the back wall away) is one of the reasons that many favor sewing from the inside out on all vascular anastomoses. Not only can the back wall be felt and pushed way with the back curve of the needle, but one can also slide the needle on its curved back within the vessel being grafted, ever so slightly, so that you can feel that the tip is free inside the lumen. The feel of the needle being in the right place is a vital sensation to know, understand, and strive for on every bite, especially those around the heel and toe of an anastomosis. However, if you cannot see the stitch well, you usually should not place it until you can see more clearly. Sometimes you can see the tip of the needle and not the rest of the needle, and this view can be adequate, of course.

Time is of the essence and you should be able to do these anastomoses fairly quickly. Perfection can be the enemy of good and, if the stitch is not ideal but acceptable, keep going. Do not wait for someone to approve every stitch. Teachers of cardiac surgery residents should try to give some sort of feedback as most stitches are placed, while trying to avoid "putting a hitch" in each stitch [Tribble 2014; Tribble 2016; Tribble 2017].

\section{DEALING WITH THE DISCREPANCY BETWEEN TWO SUTURE LINES}

It has been said that all of cardiovascular surgery involves dealing with the discrepancy between the lengths of two suture lines. As you come around the toe and head back down the second side of the anastomosis, your bites may widen out again and be a bit deeper in the side of the vessel being grafted. You are placing "the biggest patch in the world" over the middle portion of that coronary artery as you create the anastomosis, and that vessel is going to be wider there than at any other point. A fold can be created in the graft by stretching it out to align it with this second side of the anastomosis. The fold will demonstrate the part of the graft that should touch the vessel being grafted. Furthermore, this fold will 

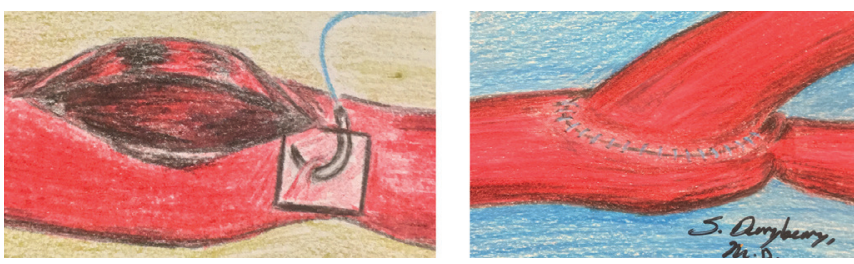

Figure 13. Catching the back wall, causing a kink.

facilitate the passage of the needle through the "just right" point on the graft (Figure 12).

As you come back to your starting point, don't go over your old stitches again. You do not need to create a two-layer anastomosis. Of particular importance is that once you get back to the original starting point, you should not take a deep final bite, because you may narrow the outflow in the heel. This last stitch, placed somewhat blindly, can catch the other side of the vessel or its back wall, causing a kink which can narrow the lumen (Figure 13).

Remember that the "strength stitches" of the anastomosis are on the sides. All you have to do is make the anastomosis hemostatic as you place the last stitch or two. When you have placed the final stitch of the anastomosis, pull up on the string and be sure that the graft sits where you wanted it. If the last bit of graft doesn't sit down optimally, consider taking one more stitch before tying. It's never easier to place a repair stitch than when you still have the original suture in your hand (Figure 14).

A couple of reminders:

- Be sure that the initial stitches taken in the heel of the graft, particularly a mammary, are very small, because deep stitches can narrow the inflow into the anastomosis. This issue is likely the most common cause of stenosis at the site of entry of a small graft, such as a mammary artery into a coronary anastomosis.

- Be sure your assistant follows the suture by holding the suture in the same direction that the needle passes through the tissue. If one pulls in a different direction too forcefully, it may tear or "slot" the coronary or the mammary.

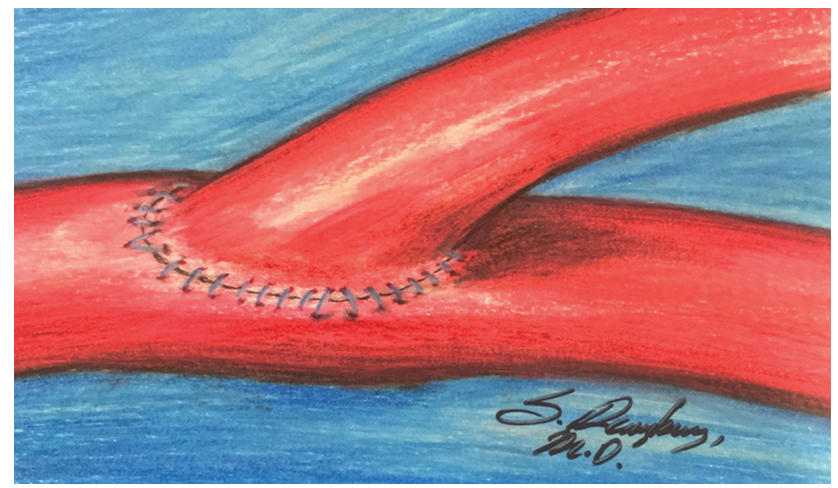

Figure 14. The completed anastomosis.
- It is always better to err on the side of putting in more stitches rather than too few. There will be fewer pleats, and the anastomosis will be more likely to be hemostatic and secure, preventing the need for repair sutures.

Handle the mammaries, veins, and coronaries as little as possible. Almost all coronaries can be opened and manipulated by picking up the nearby epicardium. The mammaries can be controlled by picking up the pedicle. The veins can be gently "spouted" with fine forceps at the start of the anastomosis, or held with two pairs of pickups near the anastomotic edge. Traction on vein grafts can also be achieved by pulling on a ligated branch while creating the anastomosis.

\section{GETTING READY TO TIE}

Once you are happy with the way the graft sits, pull up the running end of the string and ask someone to cut it. You don't want to tie with a needle still on the end of the suture that you are going to tie. Sooner or later you'll stick yourself. Furthermore, it's hard to pull a needle through the loops smoothly. Additionally, you should cut off the needle you've been sewing with, because it is usually at least a bit beaten up by the time you've put in 20+ stitches. This saves the other needle in case you need one more stitch, which, if needed, will be "blind." Therefore, you will want a sharp needle to give you the best feel for what you need to do.

Here are some more reasons that you should cut off the needle you have been sewing with, rather than breaking it:

- The cut will be precisely where you want to tie, while a break sometimes won't be in the just right place.

- Breaking the suture sometimes kinks it, which may make it a bit harder to tie.

- Perhaps most importantly, you don't want to jerk on the just completed anastomosis when breaking the suture, which is likely to happen sooner or later.

At that point (after the cut), get someone to wet your hand. (Everything works better with some lubrication, right?). Announce that you want a "handful of water" (that is, not just a little squirt). This handful of water (saline, actually) should be squirted from a bulb syringe to get an adequate amount of liquid into your hand. That liquid should be cold, by the way, when a clamp is on the aorta (so as not to rewarm the heart). The goal is not only to provide proper lubrication for the suture, but to also to wash off any blood that might make the suture or your hands sticky. You do not want there to be anything that might cause sticking, because that can lead to suture breakage, an annoying circumstance, to be sure.

While we're on the subject of dousing the hands with water, it's also good to wet both hands. As a way to help the scrub team remember that I want a lot of water on my hands, I tell them, "I'm a Baptist" (even though I myself am not) and that, "I believe in immersion rather than sprinkling." This admonition seems to be an effective way to remind the scrub team of how much liquid is really needed. Many surgeons use their non-dominant hand to 
tie, but there isn't really a compelling reason to do this in vascular anastomoses, and many tie with their dominant hand. The tradition of tying with the non-dominant hand comes from the technique of tying interrupted sutures without putting down one's instruments, which is never the case in a vascular anastomosis constructed with a running technique.

\section{TYING THE KNOT}

After the suture has been cut, the assistant should pick up the other end of the string and hold it up for you, removing the shod clamp once you've grabbed the suture where you want to hold it while tying. You should grasp this suture in your non-tying hand, with your palm facing down and the suture exiting your hand on the side of your fifth finger while not having the suture come out between your fingers. In this way you are able to:

- Not have to look around for that end of the suture.

- Grab it at just the right place.

- Avoid touching that needle.

- Make it easy for the assistant to give the shod clamp to the scrub nurse.

Other notes on tying with a monofilament suture:

- Be sure that the first two knots are set with the "just right" tension.

- Put the index finger of your tying hand below where the knot will sit, not onto the knot itself.

- The 2 ends should be in a straight line (i.e., don't pull up on the knot, at all).

- I personally don't believe it's necessary to make a knot square.

Here's why:

- To make the knot square, you'd have to change hands, which then means you're tying with the suture with the needle on it.

- Doing this (squaring the knot) distracts your attention from setting the tension on the knot.

- You can just put a few more throws on your knot, which will secure the knot and takes considerably less time than changing hands would. (Some say that you just keep tying monofilament suture "until you get tired.")

Finally, don't pull up too much at the end of the anastomosis to tie, as this action could cause "purse stringing".

\section{CUTTING THE SUTURE: TOO LONG OR TOO} SHORT?

The classic question when cutting suture is, "should the tails be too long or too short?" For monofilament suture, the answer is always, "too long." Here's why:

- They're less likely to untie, of course.
- The ends won't act like barbed wire (short monofilament suture ends are very stiff), which can hurt nearby vulnerable structures, especially those that move like lung, heart, or bowel.

- The extra monofilament won't trap bacteria, unlike silk or braided suture.

- And, a suture tail can make finding an anastomosis easier in a reoperation (recalling that every patient is a potential reop, sooner or later).

\section{THE POOR MAN'S ARTERIOGRAM: TESTING THE ANASTOMOSIS}

Before losing the exposure, test the anastomosis with a syringe filled with saline for vein grafts or by taking off the bulldog for internal mammary artery grafts. This syringe should be attached to a vein graft prior to starting the anastomosis, as flushing the vein graft not only flushes air out of the graft, but also can be used to flush blood out of the target vessel. Additionally, at times it can help to open up the anastomosis to facilitate visualization of the edges of the graft and the coronary arteriotomy. This is the time to fix any leaks, while the exposure is still optimal.

In addition to checking for leaks, flushing a newly constructed vein graft is a "poor man's arteriogram," in that you will be easily able to get some sense not only of the patency of the anastomosis, but also will be able to have a sense of the runoff of the grafted vessel. If the flow is deemed inadequate, consideration should be given to either recreating the anastomosis or to dividing the graft and leaving the vessel ungrafted. It is far better to not graft a coronary artery than to have it close in the early postoperative period.

\section{SLITS AND GROOVES: FIXING (OR AVOIDING) LEAKS IN VASCULAR ANASTOMOSES}

Once you get good at setting the graft down with each stitch, you will not need many, if any, repairs. However, repairs will at least sometimes be necessary.

If needed, repair sutures:

- Do not need to simulate the anastomotic sutures. That is, prioritize patency over hemostasis when placing repair sutures.

- Should not be simple stitches: always place at least a figure of eight. It's hard to pin down a pleat adequately with a simple stitch. Often, if you put in a simple stitch, the anastomosis will still leak on one side, or worse, on both sides, of a simple stitch.

- Place the figure of eight stitch and test the anastomosis again before tying so that more stitches can be placed. Remember that, "a figure of eight is a figure of speech." You might need a figure of 16 stitch. As an old mentor used to say: "Just keep sewing till it quits bleeding."

- Take full advantage of nearby tissue (like epicardium) to buttress a repair suture. This tissue often has some fat on it, which is one of the best instigators of the extrinsic coagulation pathway, and the epicardium has at least a bit of strength. 
Of course, the best way to fix leaks is to avoid them in the first place. Here are some tips for avoiding leaks:

- More stitches in an anastomosis are better than fewer.

- Incorporate enough tissue in each stitch to create a hemostatic anastomosis, while also taking care not to make the stitches so deep that they narrow the anastomosis, especially at the toe.

- Avoid pleats as much as possible by "setting" the graft down optimally.

- If you see that a pleat has formed, you can sometimes back track to fix it "on the fly."

- If there is a groove or fold in the vessel being grafted, you have to take a bite in the depth of that groove or fold. This concept is analogous to "stringing barbed wire over a gully," meaning "the cows will get out if the wire is not taken down into the gully."

- Avoid creating slits in the often gossamer-thin arterial wall by recognizing weaker tissue as you come upon it, and by ensuring that the assistant following the suture pulls straight out (i.e., in the direction that the vascular needle exited the vessel) rather than upwards, which might slot the artery.

Fixing a slit entails understanding that:

- The weakest point of the slit is at its apex.

- To fix the slit, you must place stitches on either side of the slit and slightly deeper than its apex, which will both lift that site and compress the slit.

- Incorporating a bit of tissue (like epicardium) can serve as a pledget.

- You can consider fixing a slit with a separate stitch.

- You must prioritize patency over hemostasis.

- You may need to redo the anastomosis. It may need to be redone with elongation of the arteriotomy in order to have the slit end up being closer the middle of the anastomosis rather than the toe. This will make repairing it less likely to narrow the outflow.

\section{LAGNIAPPE; "A LITTLE SOMETHING EXTRA": THE BEST TRICK EVER}

One of the most useful maneuvers one can use when sewing vascular anastomoses has, with some justification, been dubbed the best trick ever. It is frequently the case that when creating a vascular anastomosis, the needle that one is using for the anastomosis does not end up protruding far enough out of the tissue to be easily pulled out without causing harm to the needle tip. This issue is especially pertinent in small vessel anastomoses that are being created with fine suture and with small, delicate needles.

Some of the principles of suturing with small vascular suture needles include:

- The tip of the needle should be considered untouchable. Even the slightest contact of the tip of a delicate needle with the forceps or the needle driver can injure them, resulting in dulling the tip, or worse yet, creating a bit of a barb on the tip.

- The inner curve of the distal third of the needle should never be touched either, for the same reasons.

- However, somewhat paradoxically, the needle should also never be left uncontrolled, as it will frequently retract into the tissue of the vessel wall and, therefore, become difficult to see and extract. This principle has been described as "maintaining metal to metal at all times," meaning that the needle must be controlled by either the needle driver or the forceps throughout its passage through the graft and the vessel wall.

- The needle driver is generally kinder to the needle than the forceps.

However, these principles can be adhered to if one uses the forceps, first as a stabilizer or "anvil" on the outside of the vessel wall to press it back onto the needle tip, and then to stabilize the needle in place by gathering a bit of the tissue on the outside of the vessel being grafted and compressing it against the needle to hold it in place (Figure 15).

Once the needle has been controlled in this way, the surgeon has two primary options:

- If the needle does not protrude far enough outside the wall of the vessel being grafted, the needle, now stabilized with the forceps, can be released from the needle driver. The driver can then be used to inch the needle forward by gently pushing the end of the needle enough to reload the needle at the desired spot on the needle.

- If the needle does protrude far enough outside the wall of the vessel to be controlled by the forceps, the needle driver can be released and the needle can be extracted with the forceps.

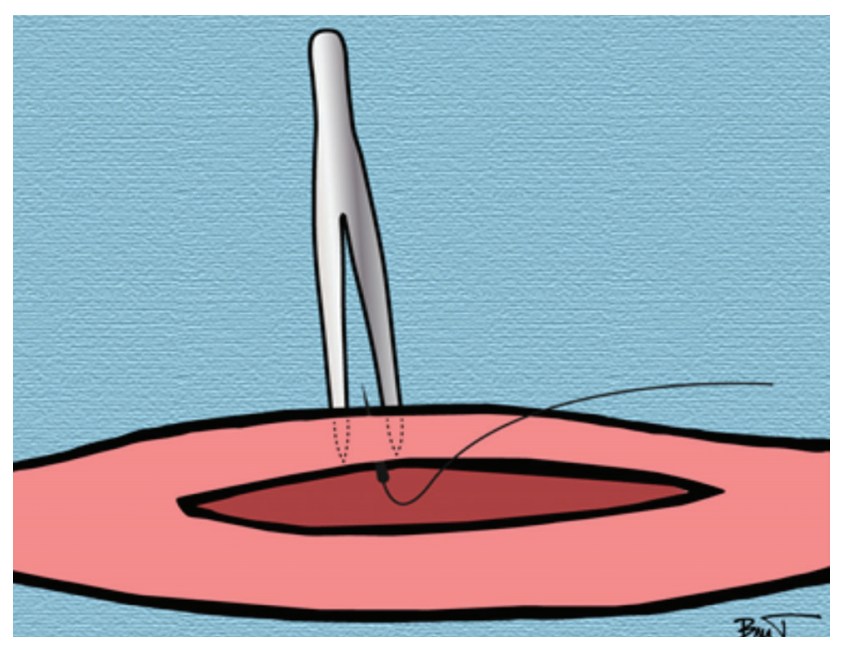

Figure 15. The forceps as an anvil on far side of vessel. 
Whichever of these maneuvers is used, the needle can eventually either be reloaded near its exit from the vessel wall, or be gently pulled with the forceps while continuing to avoid touching the distal third of the delicate needle. Avoiding holding the distal third allows the needle to be reloaded for the next stitch. Frequently, the optimal place to reload the needle will be on the towels that surround the wound, as the needle can usually be seen well against that background. You should almost never need to touch the needle with your fingers, which will help to avoid getting stuck by the needle.

This strategy will allow safe, efficient, and controlled suturing of vascular anastomoses with any size needle, though it is particularly useful with the smaller needles used for small vessel anastomoses.

\section{CONCLUSIONS}

This treatise has evolved over about a 30 year period, often with the addition of thoughts, tips, and tricks that were derived from the training of dozens of residents, which provided an ongoing impetus to think of new ways to describe and teach these techniques.

\section{ACKNOWLEDGEMENTS}

Stephen Derryberry and Ben Tribble created the artwork for this article.

Some inspiration for this treatise came from a presentation given over 30 years ago in a seminar for cardiothoracic residents held in New Orleans by Dr. Noel Mills [Ochsner 1978].

\section{REFERENCES}

Copeland J, Goldman S. 1986. Improving Results with Coronary Artery Bypass Grafting. Cardiac Surgery: State of the Art Reviews $1: 33-43$.

Kaiser L, Kron I, Spray T. 2007. Mastery of Cardiothoracic Surgery. 2nd Edition. Philadelphia: Lippincott Williams \& Wilkins.

Ochsner J, Mills N. 1978. Coronary Artery Surgery. United States: Lea \& Febiger.

Tribble C, Merrill W. 2014. The Way We Talk is the Way We Teach. J Thorac Cardiovasc Surg 147:1155-9.

Tribble C. 2016. A Practical Minded Obsession: With the Possibility and Consequence of Failure. Heart Surg Forum 19:1-4.

Tribble, C. 2017. A Shift to the Left: Teaching the Craft of Cardiac Surgery. Heart Surg Forum 20:269-73. 